\title{
Sentido, providencia y formación de la conciencia histórica: Covadonga
}

\author{
Meaning, Providence and Formation of \\ Historical Awareness: Covadonga
}

Rafael Sánchez Saus

Catedrático de la Universidad de Cádiz rafael.saus@uca.es

\begin{abstract}
Resumen: El 1300 aniversario de la batalla de Covadonga es un buen momento para reflexionar sobre el sentido providencialista que los contemporáneos dieron a aquellos hechos. Además, el presente estudio analizará la influencia que tal interpretación, asumida a lo largo de los siglos por la historiografía principal, tuvo en la Historia de España, y su sustitución por nuevos paradigmas desde el siglo XVIII y, especialmente, desde mediados del siglo XIX.
\end{abstract}

Palabras claves: batalla de Covadonga, providencialismo, sentido de la historia, neogoticismo, reino de Asturias.
Abstract: The 1300th anniversary of the Battle of Covadonga is a good time to reflect on the providential sense that contemporaries gave to those events. In addition, the present study will analyze the influence that such an interpretation, assumed throughout the centuries by the main historiography, had in the History of Spain, and its replacement by new paradigms from the eighteenth century and, especially, from the mid-nineteenth century.

Keywords: battle of Covadonga, providentialism, sense of history, neo-gothicism, kingdom of Asturias.

\section{INTRODUCCIÓN}

En 2018 se conmemoraron de forma casi imperceptible, excepto en Asturias, los trece siglos de la fecha que, aunque debatida, sigue siendo la más aceptada de entre las diversas posibles para el encuentro bélico entre cristianos y musulmanes que conocemos como batalla de Covadonga. Debemos preguntarnos cómo y por qué ese acontecimiento fue entendido e interpretado, desde fechas inmediatas o relativamente próximas a él, como el comienzo de una gran tarea de restauración de la España perdida tras la invasión de 711. Pero también hemos de ocuparnos de las derivaciones de esa perspectiva a lo largo de nuestra historia, pues dicho acontecimiento ha tenido siempre un lugar principal en la formación de la conciencia histórica de los españoles. 
Con independencia de la verdadera magnitud del choque y de sus consecuencias inmediatas, lo que no puede caber duda es que fue susceptible de una interpretación que trascendió con mucho su importancia inicial y que permitió a generaciones de españoles comprender el significado de otros muchos acontecimientos, a menudo de relieve mayor. Esto no debe sorprendernos en absoluto puesto que todo relato histórico necesita ser dotado de sentido, un sentido que para algunos existe per $s e$, aunque necesite ser descubierto y admita diversas interpretaciones, y para otros contemporáneos nuestros - aunque debemos subrayar que de manera generalizada nunca antes de esta época que vivimos- carece de verdadera realidad y es una mera construcción ideológica. No será ocioso advertir que, aun cuando esto último fuera cierto, ello no privaría en modo alguno de interés, como problema histórico, al modo en que se forjó el sentido de un acontecimiento fundante como el de Covadonga, aunque ciertamente quedaría vaciado de lo más potente de su significado.

\section{EL SENTIDO DE LA HISTORIA}

Pero si hemos de decir algo sobre el sentido de lo que pasó en Covadonga, debemos comenzar necesariamente con algunas reflexiones sobre el inagotable asunto del sentido en la historia, sobre todo ahora que, como acabamos de advertir, se trata de una cuestión no compartida por todos e incluso, para muchos, al margen del conocimiento histórico. Aunque las cuestiones que expondremos a continuación sean muy elementales, remitimos a otra obra reciente a quienes deseen ir algo más allá. ${ }^{1}$ Tanto en ella como aquí la perspectiva adoptada es la cristiana en su dimensión clásica.

La concepción cristiana del tiempo y de la historia bebe fundamentalmente de la concepción judía, la cual rompió con el carácter cíclico que otras culturas ofrecían y estableció una historia lineal dotada de principio y fin. Perfilada en sus rasgos principales ya por san Agustín, esa visión fue la propia sin excepción de toda la Edad Media cristiana y de la Modernidad hasta bien entrado el siglo XVIII. Esa concepción de la historia afirma la existencia de un sentido, de una finalidad en todo acontecer. Dicha finalidad, realizada por la providencia divina, reside en último término en el triunfo de Cristo y el establecimiento del reino de Dios en la tierra, acontecimiento al que se dirigen todos los movimientos naturales y

1 Cf. Rafael SÁnchez SAus, Dios, la historia y el hombre. El progreso divino en la historia, Madrid, Encuentro, 2018. 
las acciones humanas, aunque de forma muy distinta en unos y otras por la existencia en estas de ese factor de imprevisibilidad que es la libertad.

No hemos de insistir en que esa concepción de la historia dejó de ser compartida por todos a partir de la Ilustración, aunque es notable el hecho de que la alternativa al providencialismo no supuso en modo alguno la negación de la existencia de un sentido en la historia, sino una alteración de su finalidad: el ideal de progreso desplazó el horizonte sobrenatural a un horizonte meramente terrenal, ora idealista ora materialista. Sabemos bien a qué ideologías ha dado paso ese desplazamiento, pero el efecto más notable desde el punto de vista de la historia fue la aparición del historicismo, movimiento intelectual que veía en ella la plena realización del destino de la humanidad. La idea, surgida ya en Hegel, de encontrar en la historia la finalidad del mundo y del hombre, alcanzó tal nivel de verdadera obsesión que un gran filósofo, Karl Löwith, pudo escribir advirtiendo contra ella:"Si el mundo en cuanto naturaleza [...] realmente se disolviera algún día en el mundo de la historia, la pregunta por el sentido de esta, que hoy en día nos mueve de manera tan exclusiva, sería en efecto idéntica a la pregunta por el sentido del mundo. ¿Pero quién no percibe que esto no puede ser así?". De hecho, seguía Löwith, "la historia universal solo es universal y solo abarca todo el mundo en un sentido muy limitado". ${ }^{2}$

El panorama actual es, sin embargo, radicalmente distinto al que preocupaba a este filósofo a mediados del siglo pasado: la fe en el progreso que alimentaba al historicismo se ha desvanecido. Como muestra de ello, hace ya veinte años la filósofa Concha Roldán, embarcada en la escritura de una historia de la filosofía de la historia, señalaba los actuales"núcleos fundamentales de discusión de la historia analítica", entendiendo por tal la dedicada

"al estudio crítico de los problemas abandonando no solo el afán profético, sino también la reflexión omnicomprensiva [...] desde una clara apuesta por la contingencia histórica y la responsabilidad ética individual frente al futuro ignoto y por hacer". ${ }^{3}$

Ese abandono es hoy prácticamente general entre los historiadores, pero una vez abandonada "la reflexión omnicomprensiva", es decir, la posibilidad de encontrar un sentido en la historia, esos"núcleos fundamentales de discusión" no conducen, ni siquiera se lo proponen, a un conocimiento de la aventura humana que permita sostener el caminar del

2 Karl Löwith, El hombre en el centro de la historia, Barcelona, Herder, 1997, 167-168 (la cursiva es nuestra).

3 Concha Roldán, Entre Casandra y Clío. Una historia de la filosofía de la historia, Madrid, Akal, 1997, 191. 
hombre sobre la tierra, a un saber que aliente alguna forma de esperanza frente a lo que Mircea Eliade, testigo privilegiado de los desastres del siglo XX, llamaba"el terror a la historia". Muy al contrario, como ha señalado Giulio Botti en la Introducción a la serie de entrevistas que dedicó al historiador y filósofo católico Rémi Brague, "entre los hechos constitutivos de nuestra época hay un difuso escepticismo sobre la historia humana, considerada en su conjunto como un espacio de confusión general en la que innumerables proyectos y tentativas estarían destinados al fracaso". En efecto, en la era posmoderna la seguridad del viejo historicismo "parece haber dejado paso a un descontento radical, acompañado, según los casos, por desesperación o cinismo". ${ }^{4}$

Desesperación o cinismo, sea cual sea el acompañamiento, lo que en realidad se observa es un completo desprendimiento de conceptos hasta hace poco inseparables de la naturaleza humana. $\mathrm{Al}$ respecto, conviene traer a colación lo que hace ya quince años escribía otro filósofo afín al postmodernismo, Antonio Campillo, por cuanto reflejaba ideas hoy ampliamente compartidas en nuestra cultura:

De modo que no es posible dar cuenta de la diversidad de la experiencia humana sin intentar determinar lo que hay de "humano" (y por tanto, de común o de universal) en esa diversidad; pero, por otro lado, no es posible hablar de la"universalidad humana" como si se tratase de una "identidad" dada a priori, o como si fuera posible acceder a ella tras un largo y doloroso proceso de maduración, en un supuesto"final de la historia", sino que más bien hay que pensarla como la idea reguladora de una posible relación (en modo alguna segura) entre las diferentes sociedades y los diferentes seres a los que llamamos"humanos". La "humanidad" sería la resultante de la relación entre todas las diferentes manifestaciones de lo humano. Pero, mientras haya seres humanos, esas diferentes manifestaciones seguirán proliferando, de modo que la resultante nunca podrá ser definitiva ni definitoria. ${ }^{5}$

Estamos, pues, ante un relativismo extremo en el que el terror a la historia desemboca simplemente en su negación. En ese contexto nada queda de la vieja misión de la historia de instruirnos sobre la vida presente $\mathrm{u}$ orientar nuestras decisiones personales o colectivas. Pero es que las propuestas actuales han dejado atrás rápidamente planteamientos como los de Campillo y no dudan ya en especular con lo que Brotti define como"un retorno o una reabsorción de lo humano en el regazo de

4 Rémi Brague, ¿A dónde va la historia? Dilemas y esperanzas, Madrid, Encuentro, 2016, 9-10.

5 Antonio Campillo, Variaciones de la vida humana. Una teoría de la historia, Madrid, Akal, 2001, 146. 
la naturaleza". ${ }^{6}$ Por vez primera la humanidad ha comenzado a entrever, al menos en un plano teórico, la posibilidad de la autoextinción. Esta evolución, aunque ciertamente pavorosa, no puede ser tildada de inadvertida: como hemos podido señalar, fue entrevista hace ya mucho tiempo por quienes denunciaron la vacuidad de cierta noción historicista de progreso cuando lo que espera al final es la nada. ${ }^{7}$

\section{COVADONGA Y SU SENTIDO EN LA HISTORIOGRAFÍA ALTOMEDIEVAL}

Hemos señalado lo que antecede, aun a riesgo de que probablemente pueda parecer una interminable digresión, porque querríamos ponderar cuánto hay de inasimilable para grandes sectores del pensamiento y la historiografía actuales en la interpretación que al menos desde el siglo IX hasta nuestros días se ha venido haciendo de un episodio histórico indiscutible, pero controvertido, como resulta ser la batalla de Covadonga. La interpretación de la batalla y de sus consecuencias, la creación del reino de Asturias, que los contemporáneos hicieron solo tienen sentido en el seno de la concepción cristiana de la historia. El Dios cristiano, el Dios en el que creían los protagonistas de aquellos hechos y quienes los narraron tiempo después, hace necesaria su presencia e intervención en la historia, tanto en la de los pueblos como en la de los individuos, y hasta en el más pequeño acontecimiento, y ello mediante una acción que se expresa no solo de forma general o universal, sino bajo circunstancias concretas de tiempo y espacio. Ese convencimiento de los cristianos ha encontrado respuesta en la idea de Providencia, la cual descansa en el hecho de que la voluntad de Dios ha de cumplirse de una u otra forma, pues la historia ha de tener y tiene una finalidad espiritual. Ahora bien, eso no implica que la historia responda a planteamientos previsibles y escrutables desde la aplicación de métodos racionales.

La intervención decisiva de Dios en la historia es el mensaje que se encuentra ya en los Libros Históricos del Antiguo Testamento y en los profetas. El misterioso enviado de Dios, como nuevo David, el Mesías, nos hará entrar en la era de la paz. En la visión cristiana ese tiempo nuevo, el Reino de Dios, está presente entre nosotros con la venida de Cristo. Cristo es, pues, el centro de la historia, que es la historia de la humanidad salvada, redimida y hecha partícipe de la vida divina. Esta visión primordial llega incólume, a través de los siglos, hasta el Concilio Vaticano II.

\footnotetext{
6 Brague, ¿A dónde va la historia?, 10.

7 SÁnchez SAUs, Dios, la historia y el hombre, 10.
} 
Así, en Gaudium et Spes se lee:"El Señor es el fin de la historia humana, punto de convergencia hacia el cual tienden los deseos de la historia y de la civilización. [...] Vivificados y reunidos en su Espíritu, caminamos como peregrinos hacia la consumación de la historia humana, la cual coincide plenamente con su amoroso designio" (GS 45). Como resumía el cardenal Cottier hace unos años, en 2004, "la historia revela la pedagogía de Dios, justo y misericordioso, que desea la conversión del pueblo pecador, su retorno a la fidelidad primera. Purificado de la mancha del pecado, será restablecido en la prosperidad y la paz, signo de su amistad con Dios". 8

Resulta verdaderamente asombrosa la coherencia, la continuidad detectable entre estas definiciones de la concepción providencialista de la historia y las ideas de los cronistas asturianos del siglo IX que crearon la interpretación canónica de lo sucedido en Covadonga. Debemos ahora profundizar en los precedentes ideológicos concretos de esa interpretación y en las circunstancias que hicieron posible esa y no otra lectura de la batalla y sus consecuencias.

Muchos historiadores actuales, como Arcadio del Castillo, Julia Montenegro, Roger Collins, Armando Besga o Juan Ignacio Ruiz de la Peña han destacado la gran continuidad existente entre el primitivo reino de Asturias y el reino visigodo de Toledo. Para Ruiz de la Peña, aunque el Asturorum regnum sea una nueva realidad política, solo resulta inteligible a la luz de la tradición romano-gótica, de forma que"la incorporación de las tradiciones góticas a la armadura ideológica e institucional del reino es anterior a la atribución que la Crónica Albeldense hace de la restauración del ordo gothorum en Alfonso II". ${ }^{9}$ Esto es aceptado también, aunque con un interesante matiz diferenciador, por Luis García Moreno, quien señala la necesidad de que la nueva construcción política alumbrara una nueva "etnogénesis" gótico-astur que tuviera como fundamento la oposición Cristiandad/Islam. No podemos entrar ahora en la ardua polémica de las raíces del reino de Asturias, pero nos parece indudable que las crónicas del ciclo de Alfonso III con sus referencias bíblicas y hagiográficas hacen uso del discurso que explica la victoria de Pelayo, nos dice García Moreno, "como un iudicium Dei, producto de la potencia y misericordia divinas, como el comienzo de la consumación de una profecía de la final

8 Sánchez Saus, Dios, la historia y el hombre, 20.

9 Juan Ignacio Ruiz DE LA PeÑa, "La realeza asturiana y la formulación del poder regio", en La época de la monarquía asturiana. Actas del simposio celebrado en Covadonga (8-10 de octubre de 2001), Oviedo, Real Instituto de Estudios Asturianos y Principado de Asturias, 2002, 169 (163-201). 
derrota de los ismaelitas musulmanes por el cristiano pueblo de Gog", entendido este como el pueblo godo. ${ }^{10}$

Por su parte, reforzando ese sustrato ideológico inicial del reino de Asturias, Arcadio del Castillo y Julia Montenegro recuerdan que a lo largo del sigloVII se forjó en la España visigoda una idea muy potente, inspirada en modelos bizantinos, según la cual los godos eran el pueblo elegido por Dios, Hispania la tierra prometida y el rey godo un rey-sacerdote conforme al modelo presentado por el pueblo de Israel. Esta idea fue la que permitió plantear, según el ejemplo del Antiguo Testamento, la derrota y la pérdida del reino de Toledo como un castigo de Dios que, naturalmente, debía ser seguido del perdón por la misericordia divina cuando el pueblo hubiera purgado su pecado. Esa idea"es un motivo constante en las crónicas asturianas" y la conciencia que de ella se extrae es vivísima en el reino asturiano desde los primeros tiempos, como se demuestra por el célebre documento del 812 que recoge la donación efectuada por Alfonso II a San Salvador de Oviedo. En él se afirma que, merced a la ayuda divina, el reino visigodo había destacado sobre los demás, pero que en 711, por haber ofendido a Dios por su prepotente jactancia, sucumbió ante los musulmanes. Entonces, Dios eligió a Pelayo, quien luchó victoriosamente y salvó al pueblo cristiano:"Cristo tuvo a bien elegir, dentro de la ruina, a don Pelayo, quien elevado a la autoridad de príncipe, pudo evitar el total colapso, pues luchando victoriosamente venció a los enemigos y preservó como vencedor a la gente de Asturias" ${ }^{11}$

Esta fuerte noción de continuidad histórica, a la que es preciso sumar el efecto acumulado de otras continuidades intelectuales, centradas en el legado isidoriano, artísticas, religiosas e incluso onomásticas, es la que permitió a Ruiz de la Peña afirmar

[...] sin reservas que el espacio originario del reino de Asturias participa, desde una fase temprana de la evolución de ese reino, de una tradición cultural hispano-goda [...] que el próximo curso de los acontecimientos —la llegada al norte de inmigrantes sureños, la progresiva integración en el ámbito político del Reino de Asturias de regiones más profundamente enraizadas en esa tradición- no harán más que reforzar. ${ }^{12}$

10 Luis A. García Moreno, Covadonga, realidad y leyenda, Boletín de la Real Academia de la Historia, CXCIV (1996) 378-379 (353-380).

11 Julia Montenegro - Arcadio del Castillo, Don Pelayo y la rebelión de los astures: pervivencia y continuidad del Reino visigodo de Toledo, en Juan Ignacio RuIz DE LA PeÑA Solar - Jorge Camino Mayor (eds.), La Carisa y La Mesa. Causas políticas y militares del origen del Reino de Asturias, Pola de Lena (Asturias), Asociación de Amigos de La Carisa, 2011, 201-204 (198-211).

12 Ruiz de LA PeÑA, “La realeza asturiana y la formulación del poder regio”, 171. 
Esa sería, pues, la realidad cultural que estaría en la base de la interpretación que los círculos cortesanos, eclesiásticos e intelectuales asturianos de aquellos tiempos podían hacer de Covadonga y de los inicios del reino de Asturias. A esa base se añadieron unas circunstancias políticas y bélicas concretas que estuvieron muy en el ánimo de los redactores de las crónicas del ciclo de Alfonso III en las que se nos ha conservado el relato de lo sucedido en Covadonga. No vamos a entrar en la crítica, ni siquiera en la presentación de esas fuentes, profusamente estudiadas desde hace décadas, ${ }^{13}$ pues ello escapa por completo de nuestra intención.

No obstante, conviene recordar que las tres crónicas, la llamada Albeldense y la propiamente de Alfonso III en sus dos versiones, la Rotense y la de Sebastián, fueron escritas durante el reinado de dicho monarca, entre el 866 y el 910, el cual constituye la culminación del primitivo reino de Asturias. Se caracterizó, como sabemos, por los éxitos militares frente a los musulmanes, los avances de la repoblación al sur de la cordillera y un despegue cultural de indudable importancia muy apoyado en la presencia de numerosos mozárabes que en aquellas décadas abandonaron al-Andalus ante el irreversible deterioro de su situación y la gran anarquía que se adueñó del país. Fruto de todo ello fue la manifestación de esa ya por entonces vieja conciencia de continuidad con el pasado visigodo a la que hemos aludido, que pudo expresarse en los títulos atribuidos a Alfonso III posteriormente, como Totius Hispaniae Imperator, o el muy probablemente asumido por él mismo en alguna ocasión de Hispaniae Rex (906). Estas pretensiones no eran meros delirios de grandeza, sino que se justificaban por la profunda crisis que en esas décadas se abatió sobre el emirato cordobés, sacudido hasta sus cimientos por la fitna o guerra civil que enfrentó en un feroz todos contra todos a los grupos étnicos y religiosos que componían el inestable mosaico andalusí. Y a la realidad entrevista de que era posible el desvanecimiento del poder islámico sobre España respondieron las crónicas del momento con el remozamiento de ideas que, de forma más vaga e imprecisa, estaban presentes desde la creación del reino de Asturias. En ellas, sus monarcas procedían de la estirpe real de los godos pero no les eran imputables los cargos y pecados que habían llevado a la destrucción del reino de Toledo, estaban libres de la culpa contraída por éstos. Por el

13 Entre las ediciones más logradas y recientes, Jan PRelog, Die Chronik Alfons III. Untersuchung und Kritische Edition der vier Redactionen, Frankfurt - Berna - Cirencester, 1980; Juan Ignacio Ruiz de la PeÑa - Juan Gil Fernández, - José L. Moralejo (eds.), Crónicas Asturianas, Oviedo, Universidad de Oviedo, 1985; Yves BonnAz, Chroniques Asturiennes (fin IXe siècle), Paris, Editions du Centre National de la Recherche Scientifique, 1987. 
contrario, habían tomado el testigo de aquel reino mediante el heroico y triunfal expediente de su guerra al Islam, habían iniciado la recuperación por mediación de Pelayo, cuyas palabras en Covadonga adquirieron tono profético cuando, según la crónica Rotense, dice al obispo Oppa, presentado como hijo de Witiza y portavoz de los musulmanes: "Cristo es nuestra esperanza de que por este pequeño monte que tú ves se restaure la salvación de España y el ejército del pueblo godo", palabras que repite con pequeñas variantes el texto de Sebastián y al que da forma mucho más completa la Albeldense: “Y así por él [Pelayo] es aniquilado el enemigo ismaelita [...]Y así, desde entonces se devolvió la libertad al pueblo cristiano [...] Los de la hueste sarracena que se libraron de la espada [...] fueron aplastados por sentencia de Dios, y por la divina providencia surge el reino de los astures". ${ }^{14}$

Gran importancia tiene también lo que se afirma en la llamada Crónica Profética. Inserta en la Albeldense, incluye una adaptación al mundo visigodo-asturiano de una profecía de Ezequiel, dirigida a Ismael, es decir, a los musulmanes. El cronista transcribirá:"Entrarás en la tierra de Gog (el pueblo de los godos) con pie fácil, y abatirás a Gog [...] Sin embargo, puesto que abandonaste al Señor [...] como hiciste a Gog, así hará él contigo. Una vez que los hayas poseído en esclavitud 170 años [...] Gog te dará tu pago como tú hiciste" ${ }^{\prime 15}$ Puesto que en fecha cercana a la redacción de la crónica se habrían de cumplir los ciento setenta años que la profecía otorgaba de ocupación de España, se predecía que Alfonso III reinaría en tiempo próximo en toda ella. Entonces, cuando se cumpliera el plazo fijado por el profeta, se esperaba la llegada de la venganza sobre los enemigos y la salvación de los cristianos.

Así pues, cabe afirmar que es entonces, y sobre los mencionados elementos procedentes de la tradición visigoda, además de otros vinculados al acervo propiamente asturiano, que valoraba más en la gesta de Pelayo la salvación del pueblo cristiano que el comienzo de una posible restauración de España — como se interpretan el famoso documento de Alfonso II de 812, mediante el que dotó la iglesia de San Salvador de Oviedo, o el himno O Dei Verbum, escrito bajo Mauregato (783-788 $)^{16}$-, cuando se conforma una verdadera conciencia histórica de los

14 José Luis MARTín, “El reino de Asturias en la tradición historiográfica medieval”, en La época de la monarquía asturiana. Actas del simposio celebrado en Covadonga (8-10 de octubre de 2001), Oviedo, Real Instituto de Estudios Asturianos y Principado de Asturias, 2002, 319 (317-335).

15 Juan Ignacio Ruzz de la PeÑa, Juan Gil Fernández, José L. Moralejo, Crónicas Asturianas, Oviedo, 1985, 261-262.

16 RuIZ de LA PeÑA, “La realeza asturiana y la formulación del poder regio”, 174-176. 
acontecimientos en torno a Covadonga, enjuiciados desde entonces como la primera piedra de la restauratio Hispaniae, entendida esta en ese momento como recuperación del reino visigodo de Toledo. Pero quizá lo más interesante y lo más elocuente acerca de la riqueza y fecundidad de esta idea y de la toma de conciencia que hizo posible, es la forma en que sucesivas generaciones de españoles han visto iluminados los acontecimientos que han ido protagonizando, la historia de su patria, por el hecho germinal de Covadonga. Ello se ha hecho siempre sin ruptura con su sentido original, con el que ya fue dotado desde el principio, pero haciéndolo cada vez más rico y complejo a medida que crecía y alcanzaba madurez la realidad histórica de España.

\section{EL SENTIDO DE COVADONGA EN LA HISTORIA DE ESPAÑA}

Las crónicas asturianas del reinado de Alfonso III tuvieron una enorme influencia en toda la historiografía medieval hispana, y no solo en la castellano-leonesa, aunque especialmente en esta. Como constatara José Luis Martín, "prácticamente todas las crónicas occidentales de la Península repiten sin modificaciones sustanciales las ideas mozáraboalfonsinas, añadiendo en ocasiones datos que refuerzan la tesis de que Dios premia finalmente a los buenos godos y castiga a los responsables de la pérdida de España". ${ }^{17}$ Así en la Najerense, en la Silense, en la Crónica General, en la del obispo Lucas de Tuy, en la Crónica Latina de los Reyes de Castilla, etc... e incluso en las de los últimos siglos medievales. El carácter providencial de la batalla de Covadonga y su sentido histórico, unido siempre a la restauración del reino visigodo y de la España cristiana se refuerza cuando en su expansión reconquistadora los reinos cristianos alcanzan objetivos especialmente vinculados al pasado visigodo, como sucede con la conquista de Toledo en 1085. Un documento del propio Alfonso VI narra las motivaciones del monarca para esta conquista en términos que recuerdan extraordinariamente los que los cronistas asturianos empleaban doscientos años antes: "la ciudad (Toledo), por decisión divina, permaneció durante 376 años en poder de los moros, blasfemos del nombre de Cristo, por lo que yo, entendiendo que era vergonzoso que se invocara el nombre del maldito Mahoma... en un lugar donde nuestros santos padres adoraron a Dios... moví el ejército contra esta ciudad en la que en otro tiempo mis antecesores reinaron poderosísimos y extraordinariamente ricos". ${ }^{18}$

17 Martín, “El reino de Asturias en la tradición historiográfica medieval”, 320.

18 MArTín, “El reino de Asturias en la tradición historiográfica medieval”, 323. 
No podemos entretenernos ahora en relatar cómo se refleja lo sucedido en Covadonga y la creación del reino en la cronística aragonesa, navarra o catalana, por lo general tratando de establecer paralelismos entre la forma en que se produjo el comienzo de la resistencia asturiana y la de sus partes, pero en la medida en que fue creciendo la conciencia unitaria hispana, más allá de sus comunes comienzos en el reino visigodo, el recuerdo de Pelayo fue haciéndose cada vez más insistente y más cargado de consecuencias. Bástenos recordar un ejemplo catalán de 1496, el de las Cròniques d'Espanya del barcelonés Pere Miquel Carbonell, quien narra cómo Pelayo no fue elegido rey solo por los asturianos sino por todos los cristianos procedentes de diversas partes de España que se habían refugiado entre estas montañas por lo que sostiene que Pelayo hubo de intitularse desde el primer momento rey de España:

[...] tots los qui scaparen de la batalla del rey don Rodrigo e tots los altres qui fugiren de diverses partes de Hespanya se n'anaren a les Asturies, per quant saberen que allí lo infant don Pelayo... estaba alçat per defendre la terra. Aquí han volgut dit alguns histórichs que lo infant don Pelayo... estigué cinch anys que l'alçassen per rey, e altres han volgut dir que, com la gent fugitiva se juntà ab ell, lavòs encontinent lo alçaren per rey de Hespanya. ${ }^{19}$

La abundante y extraordinaria historiografía española de los siglos XVI y XVII mantuvo en lo esencial, como puede suponerse, el relato y el sentido de Covadonga y la hazaña de Pelayo en autores como Florián de Ocampo, Ambrosio de Morales, el padre Mariana, fray Prudencio de Sandoval o Diego de Saavedra Fajardo. ${ }^{20}$ No obstante, en los cada vez más prolijos desarrollos de la historia, en la que los discursos grandilocuentes de los protagonistas, especialmente de Pelayo, alcanzan especial refinamiento y carga ideológica, puede observarse el deseo de vincular los remotos pero siempre vivos sucesos de Covadonga con el nuevo papel de España en el mundo a través del ensalzamiento de los orígenes de una monarquía llamada a convertirse en la protectora universal de la fe católica. El sentido providencialista se expresa ahora en términos que hacen de los españoles un pueblo elegido por Dios "poco menos que para redimir a la humanidad de sus pecados y extender la fe de Cristo por el mundo" dice Ríos Saloma con sarcasmo que no vela lo exacto de

19 Citado en MARTín, "El reino de Asturias en la tradición historiográfica medieval”, 332-333.

20 Cf. Martín F. Ríos SAloma, De la Restauración a la Reconquista: la construcción de un mito nacional (Una revisión historiográfica. Siglos XVI-XIX), En la España Medieval 28 (2005) 384-389 (379-414). 
su comentario. ${ }^{21}$ Un solo párrafo de la obra titulada Corona gótica, castellana y austriaca, del diplomático y plenipotenciario de Felipe IV en el congreso de Münster, Diego de Saavedra Fajardo, nos ilustra extraordinariamente de este enriquecimiento de la visión histórica:

Grandes fueron los trabajos y calamidades con que Dios apuró la constancia de la nación Española, primero en el yugo de los romanos, después en el de los bárbaros y últimamente en el de los africanos. Pero quien con atención cargare el juicio sobre aquellos sucesos, hallará que en la misma servidumbre ganó España mayor fama que las demás naciones en la dominación [...] Pisaron los Africanos la cerviz de España por la flojedad de los godos, extinguidos ya en el ocio sus espíritus marciales, pero después pocos españoles retirados en los montes bajaron a las llanuras, y siempre desnuda la espada por el espacio de ocho siglos pelearon constantes en defensa de la libertad y de la religión, hasta que retiraron a África a los moros y ocuparon las costas de ella fundando la mayor Monarquía que se ha visto en el mundo. ${ }^{22}$

El siglo XVIII trajo nuevas perspectivas al inagotable tema de Covadonga. Como es sabido, la Historia participó en primera línea en el proceso de racionalización y secularización que sufrió toda la cultura occidental. Como ha señalado el ya mencionado Martín Ríos Saloma "la cuestión de la invasión musulmana y el inicio de la Restauración [de España] fue objeto de una revisión que tuvo como objetivo ceñir el relato a la verdad histórica y situarlo en sus correctas coordenadas cronológicas, dando pie a una nueva interpretación" ${ }^{23}$ Autores como el marqués de Mondéjar, Juan de Ferreras, el jesuita Juan Francisco Masdeu o José Ortiz y Sanz se encargaron de esa tarea en obras de diverso mérito en las que va emergiendo una nueva faceta: cada vez con más énfasis es la "nación española" la gran protagonista de la misión providencial que Covadonga encierra, una misión providencial que se entiende cada vez más en términos de recuperación territorial y de "lucha de los españoles para restablecer el orden y recuperar la nación de la que habían sido despojados por unos invasores codiciosos". ${ }^{24}$ En la obra del valenciano Ortiz y Sanz Compendio cronológico de la historia de España, publicada en siete volúmenes entre 1795 y 1803, aparece por vez primer el verbo"reconquistar" en una frase tan inequívoca como la que sigue: "La desesperación, la pena de ver la patria perdida, y sobre todo la Religión y los

21 Ríos Saloma, “De la Restauración a la Reconquista”, 391.

22 Citado en Ríos SAloma, "De la Restauración a la Reconquista", 390.

23 Ríos Saloma, "De la Restauración a la Reconquista”, 392.

24 Ríos Saloma, "De la Restauración a la Reconquista", 398. 
favores del cielo, los animó a pensar no solo en defenderse, sino también en reconquistar la patria de mano del enemigo". ${ }^{25}$

Esta nueva visión que progresivamente se va imponiendo adquiere carta de plena naturaleza en ese gran hito historiográfico que es la Historia de España desde los tiempos más remotos hasta nuestros días, de Modesto Lafuente, que comenzó a publicarse en 1850. Es Lafuente quien asume plenamente el término Reconquista con el sentido que ha llegado hasta hoy y el que acuña, sobre los textos de las viejas crónicas asturianas, la imagen triunfante en los siglos XIX y XX de la batalla de Covadonga:

En el corazón de aquellos riscos y entre un puñado de españoles y godos, restos de la monarquía hispano-goda confundidos ya en el infortunio bajo la sola denominación de españoles y cristianos, nació el pensamiento grande, glorioso, salvador, temerario entonces, de recobrar la nacionalidad perdida, de enarbolar el pendón de la fe, y a la santa voz de religión y de patria sacudir el yugo de las armas sarracenas [...] ¿Quién podría creer que aquella cueva encerrara una religión, un sacerdocio, un rey, un pueblo y una monarquía? [...] ¿Ni que aquella monarquía que se albergaba tan humilde con Pelayo en Covadonga se había de levantar tan soberbia con Isabel en Granada? ${ }^{26}$

Aparentemente, en este párrafo están todos los elementos que desde el siglo IX, quizá desde el siglo VIII, conformaron la visión sobre la batalla de Covadonga y sus consecuencias, pero hay un cambio esencial: ya no es Dios quien actúa, sino exclusivamente un puñado de españoles, eso sí cristianos, en los que nace un pensamiento grande, glorioso, salvador y temerario llamado a fructificar con el correr de los siglos. Se cercena así la raíz misma de la visión providencialista y se deja la interpretación de Covadonga al albur de las ideas dominantes en cada momento. Tiene razón Ríos Saloma cuando concluye que la obra de Lafuente y el concepto de "reconquista" que triunfa con ella es la propia de la burguesía liberal, ocupada en la construcción de la identidad del Estado-nación con base en la historia nacional. Desde nuestro punto de vista, al prescindirse expresamente de la concepción tradicional en la que Dios actuaba en defensa de los suyos para asegurar su vida y su libertad, idea que permitía todos los acrecentamientos de sentido que hemos repasado sucintamente, no solo se está reflejando la aparición de una ideología nueva que, aparentemente, mantiene las consecuencias de la anterior concepción pero sin su raíz, al mismo tiempo se produce un empobrecimiento del proyecto vinculado a la idea de España, en la que solo se enfatizará lo que nos hace distintos a los demás como clave para la comprensión de la nación

25 Ríos Saloma, “De la Restauración a la Reconquista”, 399.

26 Citado en F. Ríos Saloma, "De la Restauración a la Reconquista”, 409. 
española y de su historia. Están aquí presentes los traumas provocados por otra entonces reciente invasión de España, la napoleónica, rechazada en clave nacional pero no religiosa, ni siquiera ideológica, por la burguesía liberal que acepta los presupuestos de la Revolución Francesa. La explicación de los acontecimientos de Covadonga se convierte en deudora de la memoria, entonces vivísima, de la resistencia ante el francés.

No es el momento de implicarnos en las dificultades que este concepto de Estado-nación asentado en el liberalismo revolucionario primero, conservador después, ha tenido para establecerse en España. A ello se ha unido, de forma radical desde la Generación del 98, la pugna intelectual y política en torno al problema del ser o de la esencia de España. Una víctima importante de estos debates ha sido la propia historia de España, sometida a revisiones y manipulaciones a veces brutales para satisfacer las ideas de los bandos en presencia. El sentido de Covadonga se ha visto también involucrado en estos conflictos, junto con su legado: el sentido del reino de Asturias, de los procesos de reconquista y repoblación, de construcción progresiva de la conciencia colectiva en torno al concepto de España, etcétera. No creo engañarme si afirmo que hoy estamos ante otra nueva fase de la reinterpretación de sentido de Covadonga en clave reductora e incluso negacionista. Las interesantísimas actas del Simposio celebrado en Covadonga en octubre de 2001 y publicado al año siguiente, abundantemente citadas aquí, organizado por el área de Historia Medieval de la Universidad de Oviedo, reflejan perfectamente ese intento y las resistencias que a ello se oponían desde posiciones científicas y académicas muy sólidas. Han pasado casi veinte años de ello y la crisis de España como nación asentada de alguna forma en la tradición católica se ha agudizado hasta extremos entonces inimaginables, ¿podemos pensar que esa crisis no va a afectar a la comprensión que las nuevas generaciones tengan de lo que pasó en el monte Auseva a la altura del 718? Las ideas hoy dominantes, influidas por las sucesivas leyes de Memoria Histórica que imponen una completa reinterpretación del pasado de España, no solo de los cuarenta años de franquismo, dejarán su huella, pero también pasarán. Hoy, como los monjes que escribieron la Crónica Profética hace casi doce siglos, hemos de esperar la Restauratio Hispaniae y con ella una nueva interpretación del sentido de la historia de Covadonga y de España que permita enlazar legítimamente con lo que los hombres del alto medievo hispano descubrieron con tanta alegría y confianza: que Dios no abandona a su pueblo ni traiciona su alianza. 